\title{
The Practice about Cooperative Education between Tutor Group and Graduate
}

\author{
F. LI, F.Q. JIN \\ Harbin Institute of Technology, Harbin, P.R. China
}

\begin{abstract}
This article is related to the powerless of instructor training which result from Enrollment of graduate student. Following the example of the innovative initiatives about postgraduate education in Energy school of Harbin Institute of Technology, the Grassroots Institute effect of environmental education on the Graduate student scientific research ability training and quality education is analyzed. It is proposed that the new education system including Clear objectives, sound management system and Effective evaluation and support system. The concepts about collaborative education and knowledge sharing which the new education system carry forward promote the teachers and students grow together, particu larly in enhancing the young tutor business and ability level. The idea is worth extending and using for reference.
\end{abstract}

KEYWORD: Postgraduate education; Cooperative education; Knowledge sharing

\section{PROBLEM INTRODUCTION}

The Postgraduate training concept has changed from emphasis on imparting knowledge in the past to Comprehensive development in all aspects now. It becomes an important goal that training graduate students have the capacity for sustainable development. New situation put higher requirements to graduate students and graduate student instructor, especially the expansion of graduate enrollment to tutor brings opportunities as well as unprecedented challenges. It is not uncommon that a tutor has more than a dozen of graduate student. If the tutor has the problem in managing students, the phenomenon of powerless and busing with mentors. This can give rise to the decline in the quality of training. How to improve management efficiency of tutor, coordinate the relationship between scientific research and personnel training and balance the relationship between quality education and Research capacity has become an urgent problem to be solved. In this regard [1], the energy school of HIT combined with the actual situation of education makes an exploration based in the concept of collaboration education and knowledge sharing cooperative education.

\section{PROPOSAL OF IDEA AND SPECIFIC MEASURE ABOUT IMPLEMENTATION}

\subsection{A Proposal of concept about cooperative education and cooperative education}

In graduate training about science and engineering, to create the exchanging, shared and stimulate learning environment of Institute is a basic work. Inculcation education and Exploratory Learning complete each other. It allows student to complete the process of growing accumulation of knowledge, form the ability and moral identity, internalize life attitudes and social attitudes and complete the integration of education and self-education as soon as possible. Meanwhile, in order to achieve synergy education and knowledge sharing, education, management and services are unified and the system about environment education and self-education is set up.

\subsubsection{Management and self-management}

Scientific management through normative and systemic division is proceeded. The management is divided into daily performance and collective behavior, rather than a simple requirement or personal behavior. It can achieve a unity of selfmanagement and total management as well as the unity of Powers and responsibilities. By this way, the tutor can focus on guiding the direction and culture methods instead of daily affairs. 


\subsubsection{Education and self-education}

Mentor not only answer questions, even more important preach Tuition. The tutor should emphasize and respect dominant position of students in the educational process, stabilize the concept of career planning, allow students to do their own thing and give full of ideas and technical guidance. Effective and continuous growth is completed through the conversion from education to selfeducation.

\subsubsection{Process education and environmental education}

Effective and continuous growth needs appropriate management support and favorable environment. When ensuring the effectiveness of the process, in turn, it can promote the optimization of the environment. For students with fluidity, it is necessary to fully communicate and share accumulated ideas and generated skills through the process. Instructors not only train students to have sustainable developments but also make the Institute for Sustainable Development.

\subsection{Working system}

Using of Target management method, the task is converted to the target, which reflects the dominant position of students in the educational process, implements self-design, self-management and selfeducation, as well as reflects the global optimization, and promote common progress. It means promoting themselves, changing "want me to do" into "I do'. The measure includes developing themselves goals, adjusting and monitoring the implementation actively and collaborative personal goals and collective goals [2].

\subsubsection{Clear objectives and mode of Graduate Education}

Institute adhere to quality education as a means, emphasize interdisciplinary and focus on training graduate students the ability to find the problem and ask questions, meanwhile train students conceive research ideas, write research grant applications and the ability of looking engineering topics. It is also important to train students management ability, responsibility and teamwork to improve the overall quality of graduate students.

\subsubsection{Establish a sound management system}

To carry out the work methodically, institutes use Scientific Management as the Management Policy to create the perfect comprehensive quality, divide the work of institute and establish secretarial group, financial group, the group of academic activities, human resources group, project management group, network group, group sports activities, materials management groups, advocacy groups, network security groups, etc. It reflects the unification of structure and function, full participation and coordinated operation.

\subsubsection{The formulation of norms and management practices}

It is necessary to formulate Job specification to working group and set out behavior specification to research group. Its contents include the specific content of the work, time and quality standards, collaborative relationships among the tasks of the working group, the rights and obligations of group members, the daily behavior norms and so on.

\subsubsection{Establishing an internal information system}

To promote the implementation of the work and management, institutes establish Digital Library and its management system, the internal cyberspace of institute, the recording system of work plans and affairs, internal communication and management query system. At the same time, institutes set up column of approaching master, advocate academic and humanistic spirit, establish open-shelf management system performed by instructors and graduate students which can check out Doctoral personal archives.

\subsubsection{Establish a working innovation mechanism}

"Good idea comes from discussion", which means cultivation of innovative thinking creative atmosphere should be focused on, such as advocate for open communication, establish research group's academic reporting system ,promote academic activities among college students, provide sufficient information resources and communication opportunities and so on. Meanwhile, the institute rewards the management and academic innovation work, as well as trains through the in-house website's column to promote the study of innovative law and methods.

\subsection{Evaluation System}

Evaluation system includes the evaluation objectives, evaluation methods, evaluation operation, evaluation index, evaluation results, etc. Its design idea is to reflect the tutor's guidance and unify between environmental education and the process of education, self-education and selfmanagement. The characteristics of institute evaluation system are that realistic evaluation is the main method and quantitative evaluation is minor; combination between self-assessment and environmental assessment; unification between process evaluation and outcome evaluation; conduct 
both individual assessment and evaluation of work groups simultaneously.

\subsection{Support System}

Support system includes the basic hardware environment construction and funding and other material support of Institute; determines routine required behavior as the work system to ensure the institutional support's effectiveness; and also includes emotional support, such as target stimulation, value inspiration, examples motivation, cultural influence within a team ect.

\section{EXPLORATION AND PRACTICE}

\subsection{The Extension of Student's Academic Level}

Just as the advanced power control and reliability institute of energy engineering, in accordance with the such system operation ,has held 354 colloquium, besides the number of these, which graduate doctors had published during their study time, reached to 10.8 on average; postgraduates from the Institute of combustion engineering founded and published the nationally renowned online journal, as well as spontaneously organized the National Conference attended by more than 200 people for several times. Its registered user forums reached more than 25,000 people, independent of IP traffic over 740,000 and nearly 20,000 hits a day, which made the professional technical website become the largest one in this area of expertise.

\subsection{The Enhance of Management in Research Group}

Institute cultivated the academic sensitivity of a postgraduate, rigorous attitude to study, and a scientifically logical way of thinking, by the guidance and discussion of postgraduates' program, funds project applications, scientific research , scientific literature's writing and other aspects; To improve postgraduates' management capabilities, team spirit and sense of ownership, there was a division of labor among team members; To train a postgraduate's ability of self-design, selfmanagement, and self-education, postgraduates and their tutors formulated jointly the students' longterm development program, mid-term goals and short-term work plan; Guiding students Through conscious guidance such as reading the classics regularly and so on to postgraduates made them improved their humane quality generally. The backbones trained by institute have become the organizers of the school's various academic forums and academic communication.

\subsection{The Enhance of Student management efficiency}

All members of the Institute are responsible for the management work and the division of labor, playing different roles, their duties, co-management between teams formed a tense but lively, busy but not chaotic working atmosphere of laboratory. To share a variety of academic information for everyone, the research institute's digital library was founded; to share the meeting information, a relevant conference information webpage was made; to make a review by the tutors from time to time and strengthen mutual understanding and information exchange of teachers and students, the institute established a week planning system; to promote the guidance and development of management work continuously, the management team monthly planning system was also established; to record, manage and query academic discussion activities, the institute set up a colloquium recording system; the establishment of the laboratory library management system facilitated everyone had an access to literature; the institute built an Email and maillist system which is convenient to exchange and share information among members of the laboratory; The establishment of the management query system realized staff management, promoted exchanges and supervision and improved work efficiency.

Through advocate the concept of cooperative education and knowledge sharing, as well as the implementation of scientific management, the institute achieved environmental education, improved not only the overall quality and research capacity of postgraduates, but also the work efficiency and working level of instructors, which, as a result, enabled the institute and students' effective and continuous growth.

\section{REFERENCES}

[1] Chang-kun Chen \& ShenBing Yin. 2011. Collaborative graduate innovative team training teacher role in the process of research of "Journal of changsha railway institute: social science" 2011(04):231-233.

[2] Yang Wei. 2006. Collaborative innovation of postgraduate education of "Degree and postgraduate education" 2006 (06):3. 